AIAA 2002-2929

Development of Pneumatic Channel Wing Powered-Lift Advanced Super-STOL Aircraft

Robert J. Englar

Georgia Tech Research Institute

Aerospace, Transportation \& Advanced Systems Lab Atlanta GA 30332-0844

Bryan A. Campbell

NASA Langley Research Center

Configuration Aerodynamics Branch

Hampton, VA 23681-2199
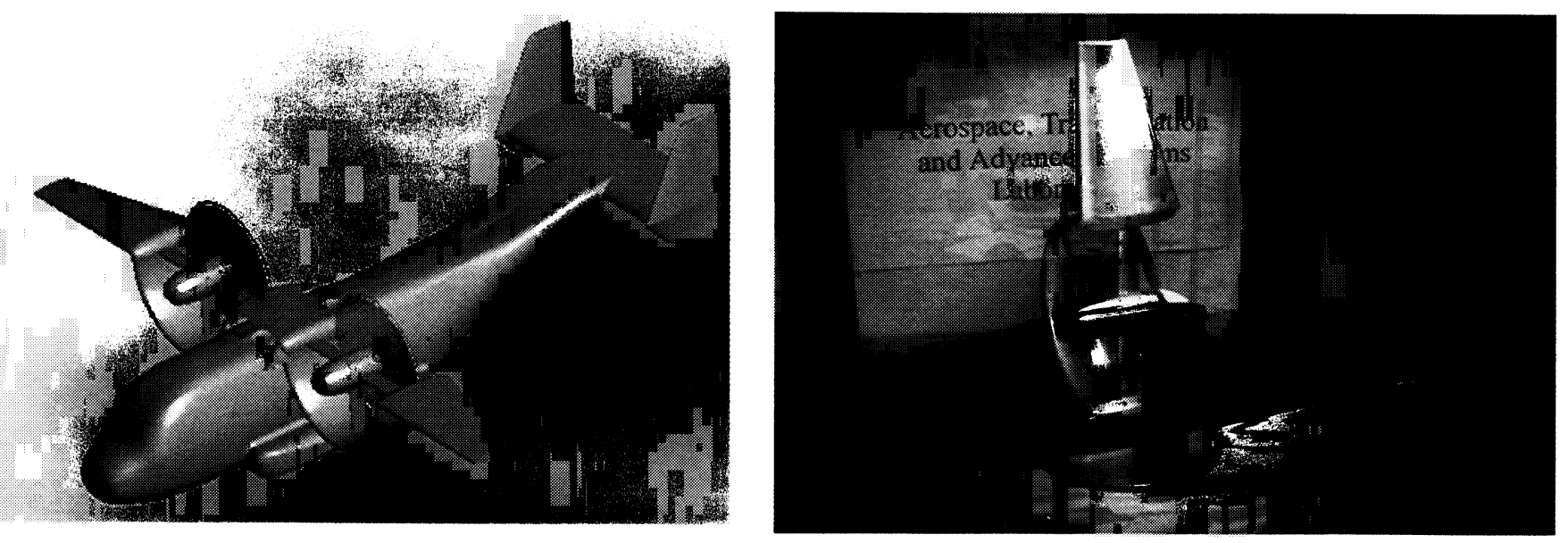

$20^{\text {th }}$ AIAA Applied Aerodynamics Conference 24-26 June 2002
St. Louis, Missouri

For permission to copy or to republish, contact the copyright owner named on the first page. 


\title{
DEVELOPMENT OF PNEUMATIC CHANNEL WING POWERED-LIFT ADVANCED SUPER-STOL AIRCRAFT
}

\author{
Robert J. Englar* \\ Georgia Tech Research Institute (GTRI) \\ Aerospace, Transportation and Advanced Systems Laboratory \\ Atlanta, GA 30332-0844 \\ and \\ Bryan A. Campbell** \\ NASA Langley Research Center (LaRC) \\ Configuration Aerodynamics Branch, MS286 \\ Hampton, VA 23681-2199
}

\begin{abstract}
The powered-lift Channel Wing concept has been combined with pneumatic Circulation Control aerodynamic and propulsive technology to generate a Pneumatic Channel Wing configuration intended to have Super-STOL or VSTOL capability while eliminating many of the operational problem areas of the original Channel Wing vehicle. A preliminary design study of this pneumatic vehicle based on previous windtunnel and flight-test data for the two technologies integrated into a simple Pneumatic Channel Wing (PCW) configuration showed very strong Super-STOL potential. Wind-tunnel development and evaluations of a PCW powered model conducted at Georgia Tech Research Institute (GTRI) have shown substantial lift capabilities for the blown configuration $\left(C_{L}\right.$ values of 8.5 to 9.0). Variation in blowing of the channel was shown to be more efficient than variation in propeller thrust. Also revealed was the ability to operate unstalled at very high angles of attack of $40^{\circ}-45^{\circ}$, or to achieve very high lift at much lower angle of attack to increase visibility and controllability. In order to provide greater flexibility in SuperSTOL takeoffs and landings, the blown model also displayed the ability to interchange thrust and drag by varying blowing without any moving parts. This paper presents these experimental results, discusses variations in the configuration geometry under development, and extends this integrated technology to advanced design studies of PCW-type vehicles.
\end{abstract}

\section{INTRODUCTION / BACKGROUND}

The ability to achieve Super-STOL or V/STOL capability with fixed-wing aircraft has been an attractive goal in the aerospace community for over 50 years. The impetus toward its achievement has historically been the numerous benefits associated with very-short to zero-field-length operations of non-rotary-wing aircraft. While such capability has direct

* Principal Research Engineer; Associate Fellow, AIAA

** Principal Investigator; NASA LaRC

Copyright $\bigcirc 2002$ by Robert J. Englar. Published by American Institute of

Aeronautics \& Astronautics, Inc. with permission. application for military missions such as those of a tilt-rotor or tilt-wing aircraft, there also exists an additional need for simple/reliable/effective personal and business-sized SuperSTOL or VSTOL aircraft operating from remote or small sites as well as increasingly dense urban environments. The development of simple efficient aeropropulsive technology and corresponding low-speed control systems to make this possible is a goal which now seems practical due to technical breakthroughs in pneumatic and powered-lift aerodynamic technologies.
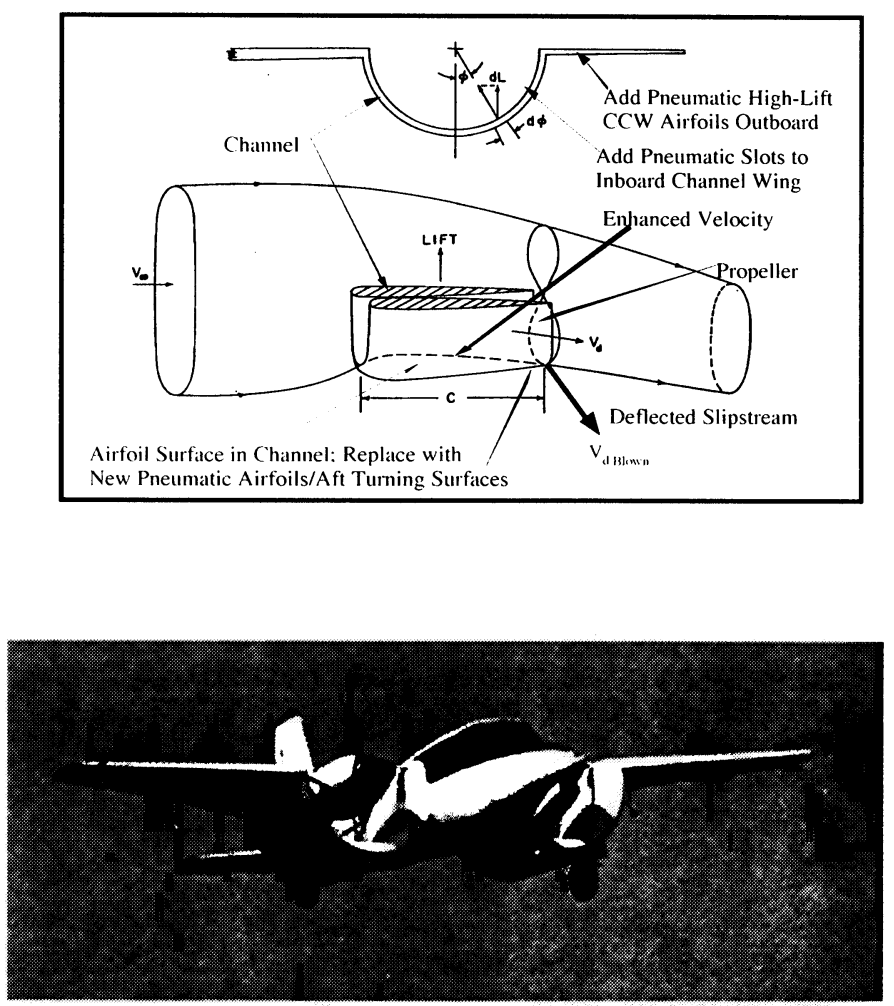

Figure 1-Basis of Channel Wing Propulsive Aerodynamics, and Current Pneumatic Developments at GTRI/NASA, plus 1950s Custer Channel Wing Aircraft in flight (Refs. 2 and 3) 
Two promising technologies to evolve from earlier STOL/VSTOL research are the Custer Channel Wing poweredlift configuration and the Circulation Control Wing (CCW) pneumatic high-lift concept. Through innovative use of the propeller slipstream, the Channel Wing airplane developed by Willard Custer (Refs. 1, 2, 3) was able to achieve significant lift coefficient and efficient downward thrust deflection without varying the high-lift configuration geometry. This poweredlift technology, tunnel-tested by NACA in 1953, (Ref. 1) and then flight-tested and further developed by Custer in the late 1950's (Ref. 2), employed the concept shown in the sketch of Figure 1 (from Ref. 3). In essence, the propeller located at the very trailing edge of the $180^{\circ}$-arc circular channel in the wing further increased the velocity over the channel's upper surface and augmented the circulation and lift there in much the same manner as a flap, but perhaps to a greater extent. Lift was also augmented by the deflected slipstream behind the channel such that

$$
\Delta \mathrm{C}_{\mathrm{L}}=\mathrm{C}_{\mathrm{T}} \sin \left(\alpha+\delta_{\text {slipstream }}\right)
$$

However, while in-flight lift coefficients nearing 5 were generated by thrust coefficients also nearing 5 (Ref. 3), the flight-tested Custer Channel Wing aircraft demonstrated a number of drawbacks associated with low-speed handling, cruise drag, stability \& control, high-incidence operation, and one-engine-out scenarios, including:

- much of the high $\mathrm{CL}_{\mathrm{L}}$ was from redirected thrust, less was from circulation lift augmentation

- high drag could result from the channel's surface area

- asymmetric thrust yields asymmetric moments \& instability

- channel leading-edge and trailing-edge separation could occur at high angle of attack, $\alpha$

- poor low-speed control from conventional aerodynamic surfaces at low speeds

- nose-down pitch from aft propeller loading on the wing

- non-uniform flow around the prop at high $\alpha$

- poor lift/drag ratio

- high-angle-of-attack operation could cause poor visibility and control

- one-engine-out control problems

To alleviate these shortcomings, preliminary research has been accomplished under a NASA-Langley-sponsored program at Georgia Tech Research Institute (GTRI) which is investigating adapting Circulation Control pneumatic technology (Refs. 4 and 5, for example) to dramatically improve the Channel Wing configuration. As Figure 1 suggests, the new pneumatic configuration thus developed combines blowing on curved surfaces at the channel trailing edge to greatly augment the lift and thrust deflection without using high angle of attack. It also employs blown Circulation Control Wing technology on the outboard wing panels to further augment lift and low-speed controllability while providing additional drag when needed for slow-speed approaches down steep glide slopes for Super-STOL. Based on earlier CCW/Upper Surface Blowing (USB) wind-tunnel and full-scale data (Refs. 6 and 7) and CCW flight test data from an
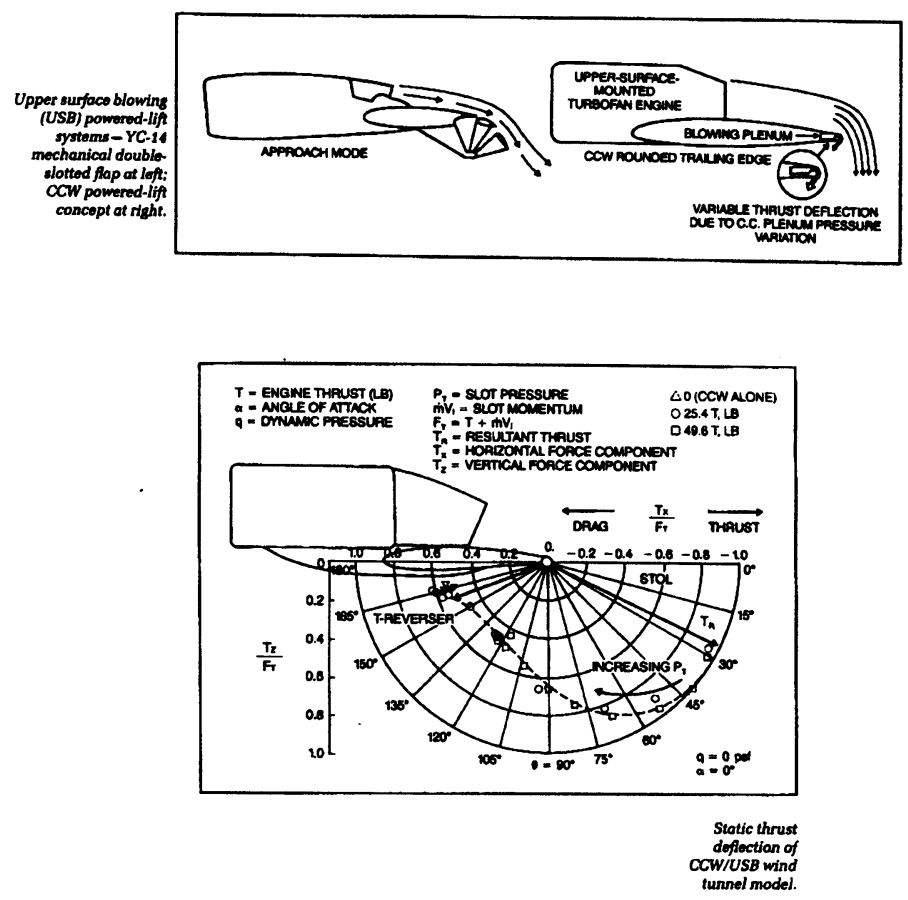

Fig. 2 - Previously Developed Circulation Control Wing/ Upper Surface Blowing Powered-Lift Concept (Ref. 6)

A-6 STOL-demonstrator program (Ref. 8), the predicted lift and drag capabilities for the Pneumatic Channel Wing configuration were expected to offer great Super-STOL promise. Reference 9 details these early predictions before the current wind-tunnel test data were available.

Figure 2 shows the CCW/USB concept, where tangential blowing on a highly curved trailing edge augments flow field entrainment, increases circulation and deflects thrust to add more incremental lift. Thrust deflection angles of $165^{\circ}$ caused by blowing were measured experimentally on windtunnel models (Refs. 5 and 6). This concept provides pneumatic STOL, VSTOL and thrust-reversing capabilities without any moving parts. $\mathrm{CCW}$ alone employs a similar tangential-blowing configuration but without the pneumatic thrust deflection. CCW airfoils have generated measured 2-D lift augmentations of 80 times the input blowing momentum (Refs. 4 and 5). When flight-tested on an A-6 flight demonstrator, CCW showed a $140 \%$ increase in useable highlift, employing only half of the available bleed air from the aircraft's standard turbojet engines (Ref. 8). Figure 1 shows how these blown flow-entrainment devices would be arranged to enhance the effectiveness of the Pneumatic Channel Wing (PCW) configuration. In addition, the $\mathrm{CCW}$ lift capability can be applied differentially outboard to generate very large rolling and yawing moments which are essential for controlled flight at very low Super-STOL speeds. Powered lift coefficients up to 15 were predicted to result for the blown channel wing section, with an additional 4 to 5 possible from the outboard CCW (Ref. 9). For comparison, the Custer Channel Wing aircraft generated $\mathrm{C}_{\mathrm{L}}$ just under 5; a conventional slotted flap 
on this wing geometry would generate $\mathrm{CL}_{\mathrm{L}}$ from 2 to 3 . Initial takeoff predictions (Ref. 9) showed that these PCW capabilities could produce hot-day takeoff ground rolls of under $100 \mathrm{ft}$ for typical mission weights, and even zero ground roll under certain conditions.

As part of an ongoing program for NASA Langley Research Center to develop this Pneumatic Channel Wing concept, GTRI and NASA have teamed in an experimental development program being conducted at GTRI, and have provided aerodynamic and propulsive data input for design studies being conducted at both NASA and GTRI. This current AIAA paper will present these experimental results and discuss effects deriving from variations in PCW geometry, propeller thrust and channel blowing.

\section{EXPERIMENTAL APPARATUS AND TEST TECHNIQUES}

A wind-tunnel development/evaluation program was conducted at GTRI on a generic twin-engine Super-STOL-type transport configuration, Figure 3, using the 0.075-scale semispan model shown in Figure 4. Here, a variable-speed electric motor was installed in the nacelle, which could be located at various positions in the channel, and which drove 2-bladed or 3-bladed propellers of various diameters and pitch. Also variable was the height of the blowing slot located at $95 \%$ of the channel chord length, as well as the blowing momentum coefficient and portions of the slot arc length which were blown. Behind the slot, the rounded trailing edge curved only $90^{\circ}$ (rather than the more conventional $180^{\circ}$ of typical CCW configurations) for an anticipated maximum thrust deflection of around $90^{\circ}$ plus $\alpha$. It was already known (Fig. 2) that thrust deflections up to $165^{\circ}$ were a possibility. Here, the momentum coefficient is defined as

$$
\begin{gathered}
\mathrm{C}_{\mu}=(\text { mass flow rate } * \text { jet velocity }) /(\text { dynamic pressure } * \\
\text { wing planform area })=\mathrm{m} \mathrm{Vj} /(\mathrm{qS}) .
\end{gathered}
$$

This semi-span model configuration was mounted on an under-floor balance with air supply and automated pitch table in the GTRI Model Test Facility 30" x 43" x 90" test section. Tunnel wall boundary layer near the test section floor was eliminated by use of tangential floor blowing. In a follow-on version of this configuration, both the leading edge and the trailing edge of the outboard $\mathrm{CCW}$ wing section will be blown. For the Phase I data to be presented herein, the outboard wing remained unblown with no leading- or trailingedge flap deflections. Therefore the emphasis in the following data is on the performance of the inboard blown Pneumatic Channel Wing configuration.

\section{WIND-TUNNEL EVALUATIONS and RESULTS}

Test techniques employed in the subsonic tunnel evaluation of this pneumatic powered-lift model are similar to those employed and described in Refs 10 and 11 for blown airfoil and semi-span models, except that special additional techniques were employed to account for the installation of the active propeller in the channel (see below). Some 196 wind-

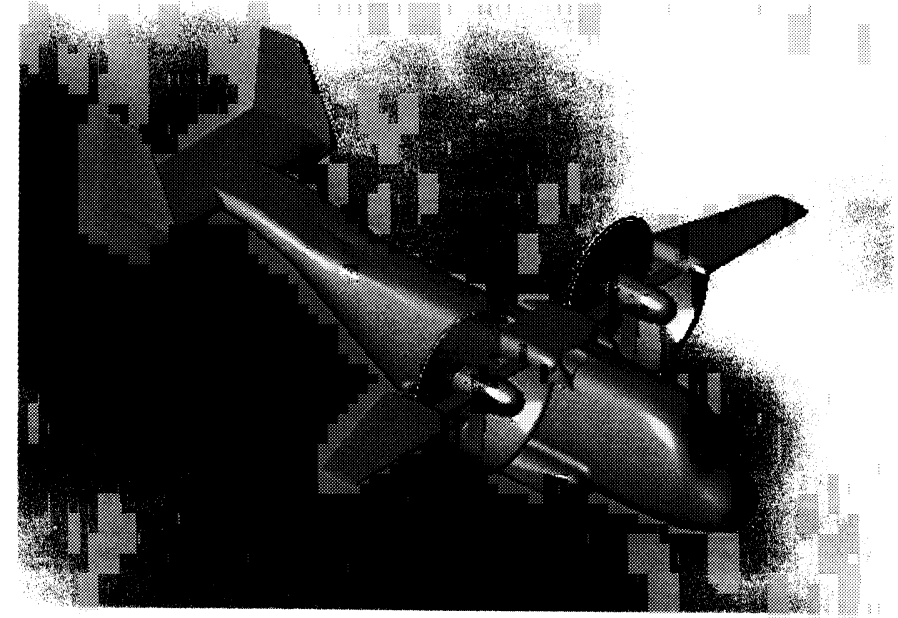

Fig. 3 - Conceptual Pneumatic Channel Wing Super STOL Transport Configuration

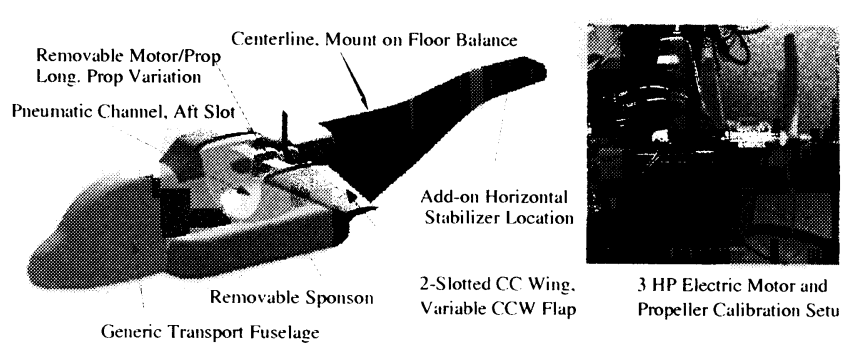

Half-span Powered Pneumatic Channel Wing Model with 3 Air Blowing Slots per wing (1 in Channel, 2 in CCW)

Pneumatic Channel Wing Model Mounted on Floor Balance in the GTRI Model Test Facili

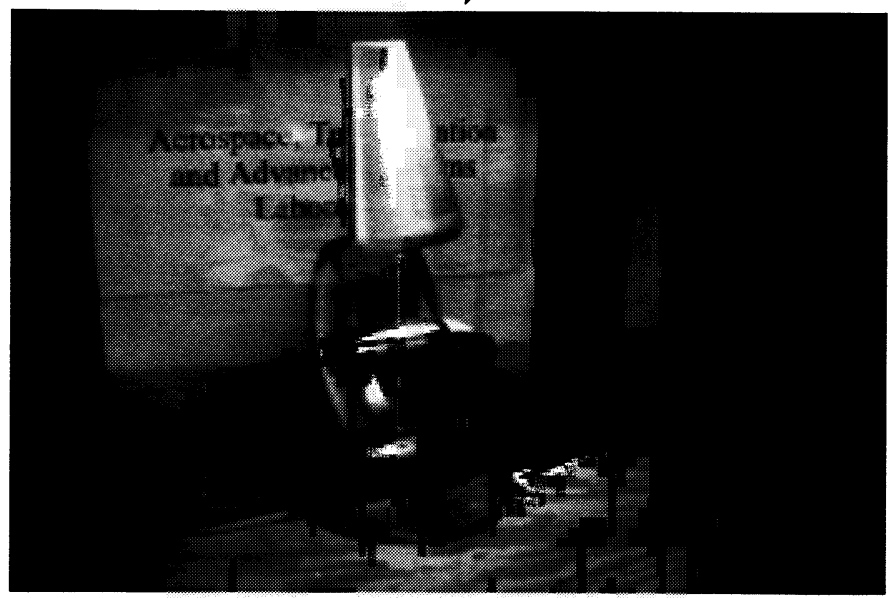

Fig. 4 - Pneumatic Channel Wing/CCW Semi-span Model Design, Power Unit, and Installation in GTRI Model Test Facility Research Tunnel (Outboard CCW Unblown Here) 
tunnel runs were conducted during the present test program at GTRI (including propeller calibrations) to develop these blown-configuration geometries and to evaluate their aeropropulsive characteristics. A typical run consisted of a sweep (incremental variation) of prop thrust or blowing pressure at constant angle of attack and wind speed. Also, angle of attack sweeps or dynamic pressure (velocity) sweeps were run at constant thrust and blowing coefficients, $\mathrm{C}_{\mathrm{T}}$ and $\mathrm{C} \mu$. Typical test results are presented in the following sections to demonstrate how these various parameters affected overall performance.

\section{Tunnel Test Results}

In Figures $5 \mathrm{a}$ and $5 \mathrm{~b}$ are shown the effects on lift and drag coefficients of blowing the channel trailing edge without the prop installed (i.e., $\mathrm{C}_{\mathrm{T}}=0$ ), but with the engine nacelle in place. Notice the ability of the blowing to more than double the $C_{\text {Lmax }}$ of the unblown configuration with virtually no reduction in the stall angle, $\alpha_{\text {stall }}$. The $C_{L}$ values shown are comparable to or greater than those which would normally be generated by more-complex moving mechanical flaps. Notice also the ability of the blowing at $\alpha=0^{\circ}$ to increase $C_{L}$ by a factor of nearly 10 over the unblown value. At $\alpha=0^{\circ}$, blowing at $\mathrm{C} \mu=0.30$ yields $50 \%$ more $\mathrm{C}_{\mathrm{L}}$ than the $\mathrm{C}_{\mathrm{L} \max }$ of the unblown configuration. In Figure $5 \mathrm{~b}$, the drag polars at constant $\mathrm{C} \mu$ are typically quadratic in $\mathrm{C}_{\mathrm{L}}$. Below where the stall begins, they follow essentially the same single curve, using blowing to progress to each successive higher $C_{L}$ region.

Addition of the propeller to the channel brings into play the powered-lift characteristics of the Pneumatic Channel

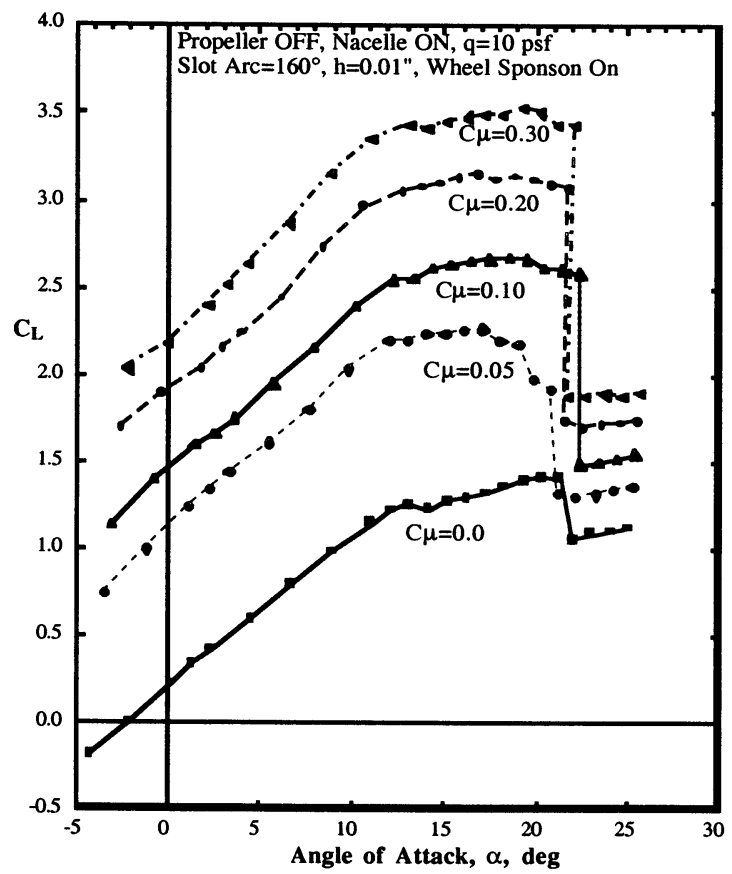

Fig. 5a- Measured Blown Lift Capability of Pneumatic Channel Wing Model Without the Propeller Installed

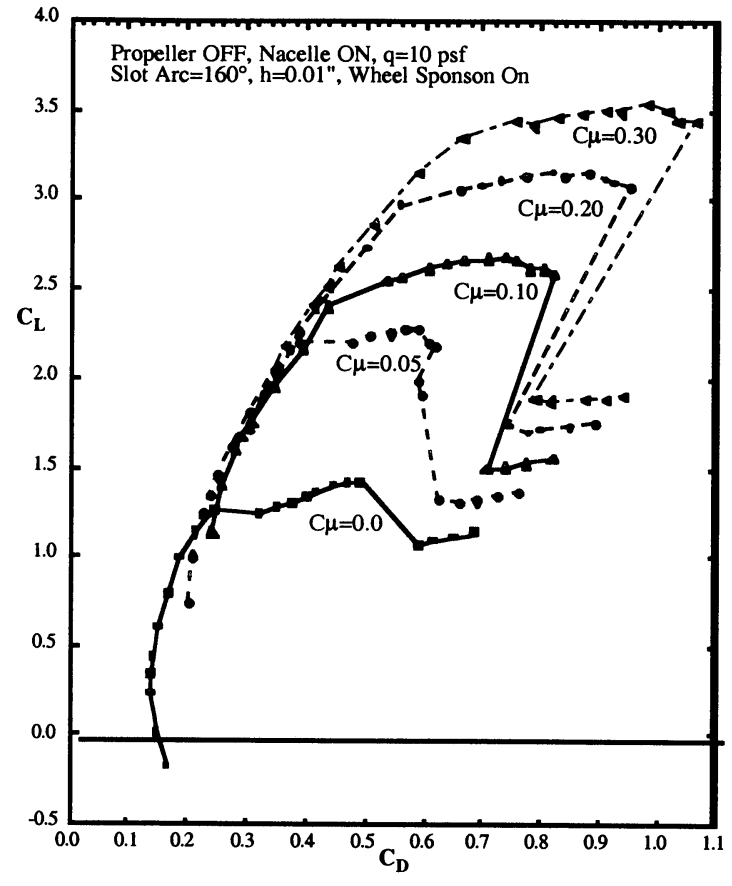

Fig. 5b - Measured Blown Drag of Pneumatic Channel Wing Model Without the Propeller Installed

Wing configuration. Figure 6 , for $\alpha=0^{\circ}$, shows the variations in $C_{L}$ and $C_{D}$ with thrust coefficient $C_{T}$ for fixed values of blowing coefficient. Here, in order to recognize the direct thrust component to lift and drag, thrust coefficient is defined as $C_{T}=T /(q S)$, where $T$ is the calibrated uninstalled wind-on prop-alone (not-in-the-channel) thrust at the proper advance ratio, i. e., representative test dynamic pressure, $q$.

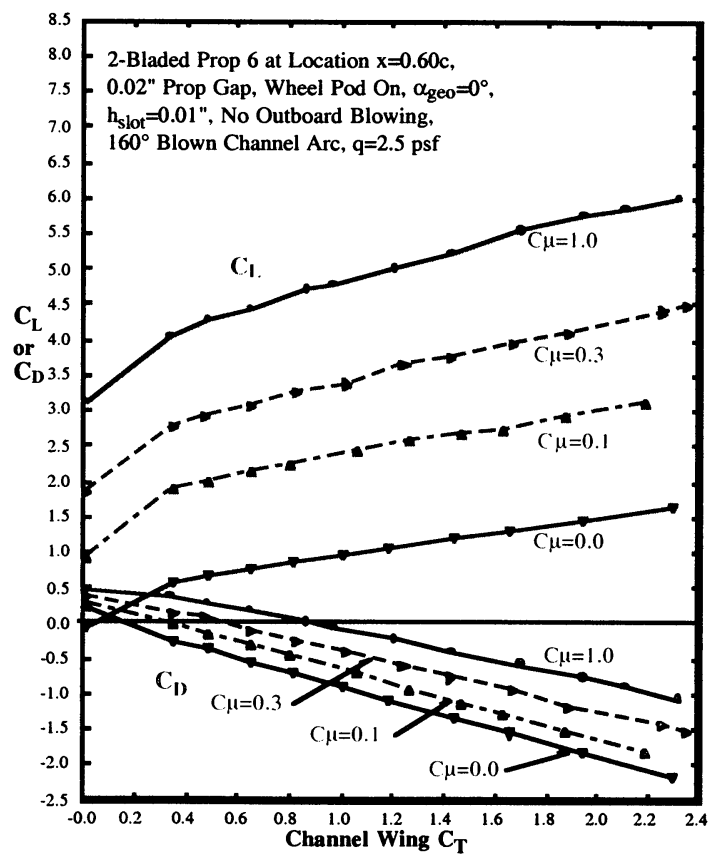

Fig. 6- GTRI Test Results: Prop Thrust Effects on Lift and Drag at Constant Blowing and $\alpha=0^{\circ}$ 


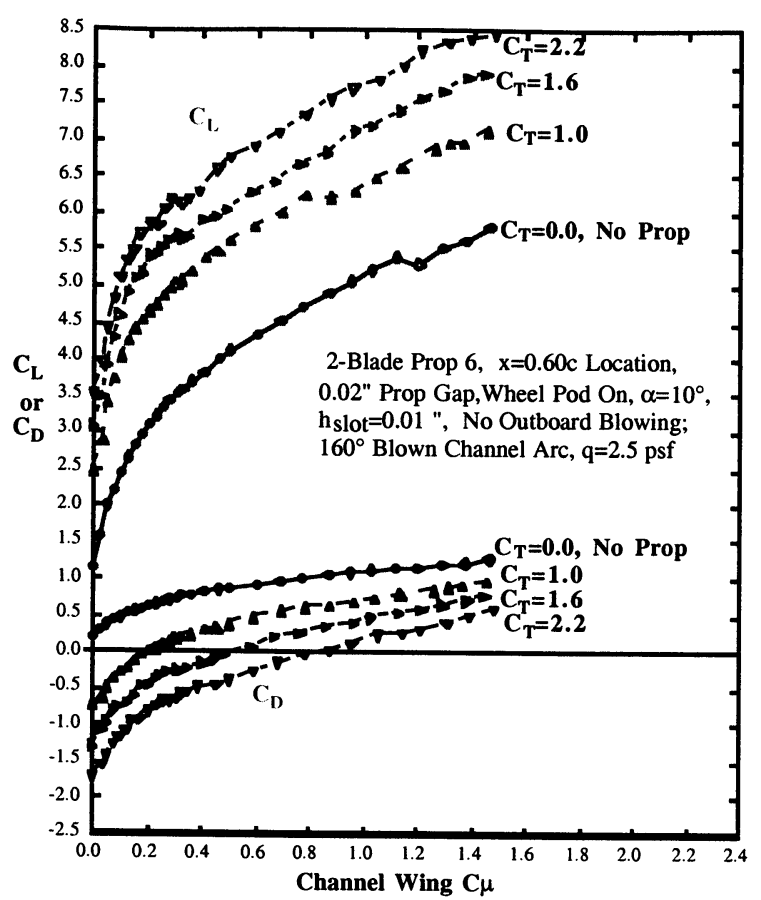

Fig. 7 - Blowing Variation Effects on Lift and Drag at Constant $\mathrm{C}_{\mathrm{T}}$ and $\alpha=10^{\circ}$

The reference area $S$ is the wing semi-planform area. These thrust values were determined prior to installation in the channel by testing the prop alone in the tunnel at various RPMs and tunnel speeds. Then, calibration curves of $T$ vs RPM were input to the data reduction program at given test wind speeds. Thus $\mathrm{C}_{\mathrm{T}}, \mathrm{C}_{\mathrm{L}}$ and $\mathrm{C}_{\mathrm{D}}$ are directly comparable on a common reference basis to determine force contributions from installed thrust. This avoids the difficulty which would be caused by using the standard helicopter thrust coefficient, which is based on rotor (or prop) geometry rather than wing area. Also, note that measured $C_{D}$ thus obviously includes the input thrust, which cannot reasonably be separated from the aerodynamic drag alone once the prop is in the channel. Measured $C_{D}$ can thus be negative. After the initial low values of $C_{T}$ are exceeded, $C_{L}$ increases nearly linear with $C_{T}$, and $C_{D}$ reduces nearly linearly.

Figure 7 shows that incremental lift augmentation due to blowing is much greater than due to $\mathrm{C}_{\mathrm{T}}$ (from Figure 6). Here at $\mathrm{C}_{\mathrm{T}}=2.2$, the blown configuration generates $\mathrm{C}_{\mathrm{L}}$ around 8.5 at $\alpha=10^{\circ}$. The flight-tested Custer Channel Wing (Ref. 3) generated $\mathrm{C}_{\mathrm{L}}=3.1$ at this $\mathrm{C}_{\mathrm{T}}$, but required $\alpha=24^{\circ}$ $25^{\circ}$. Note also that increased blowing at a constant $C_{T}$ yields increased drag (rather than thrust recovery) which can be quite essential for Super-STOL approaches and landings. These lift comparisons in Figures 6 and 7 show that lift increases more efficiently by increasing blowing than by increasing thrust. In the Figure 8 plot is shown the variation in lift and drag with
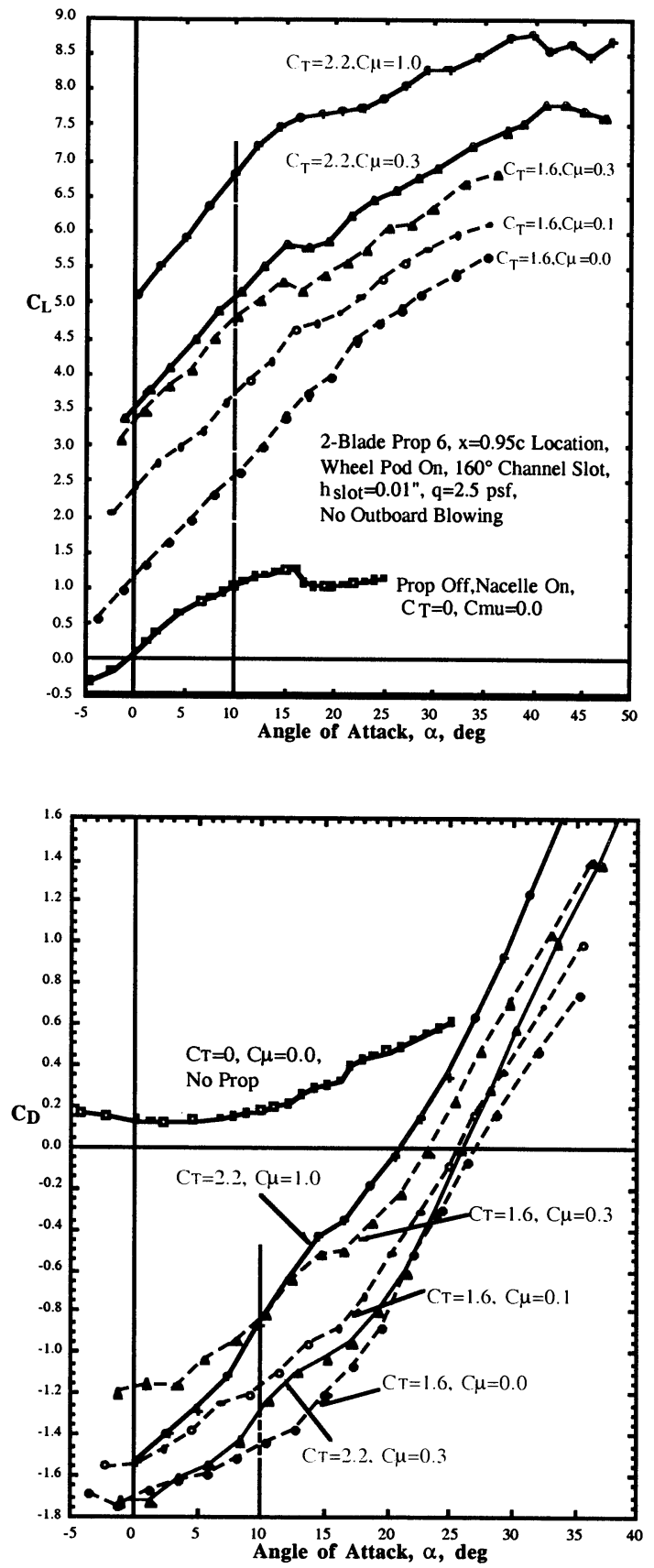

Fig. 8 - Effects of Blowing and $\mathrm{C}_{\mathrm{T}}$ on Lift Coefficient, Stall Angle and Drag Coefficient

angle of attack for the blown powered configuration in comparison to the unblown baseline configuration without the prop. Here, flow visualization showed that the initial stall $\left(\alpha=15^{\circ}-17^{\circ}\right)$ seen for most of the lift curves corresponded to stall of the outboard unblown wing section, while the blown channel wing section then continued on to stall angles of $40^{\circ}$ $45^{\circ}$ and $C_{L}$ values of 8.5 to 9 . Notice that $C_{D}$ including thrust increases from negative to positive values as incidence increases. 


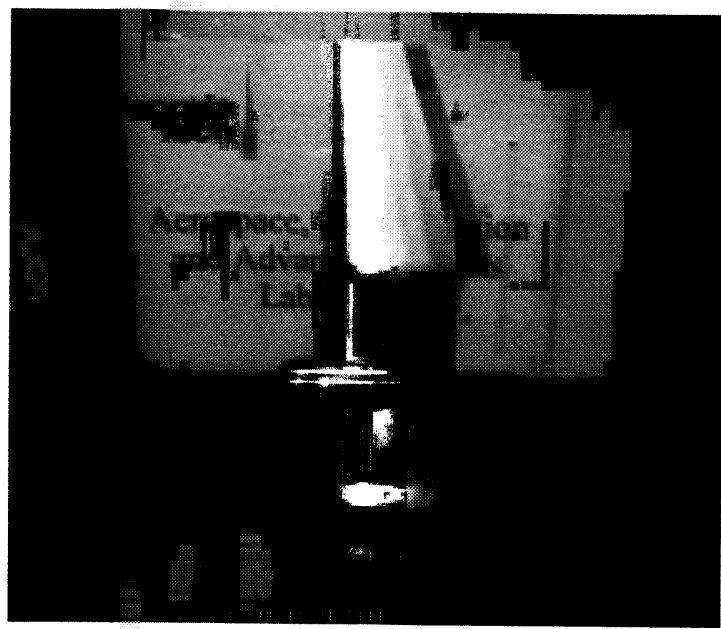

Prop $x / c=0.60 c$

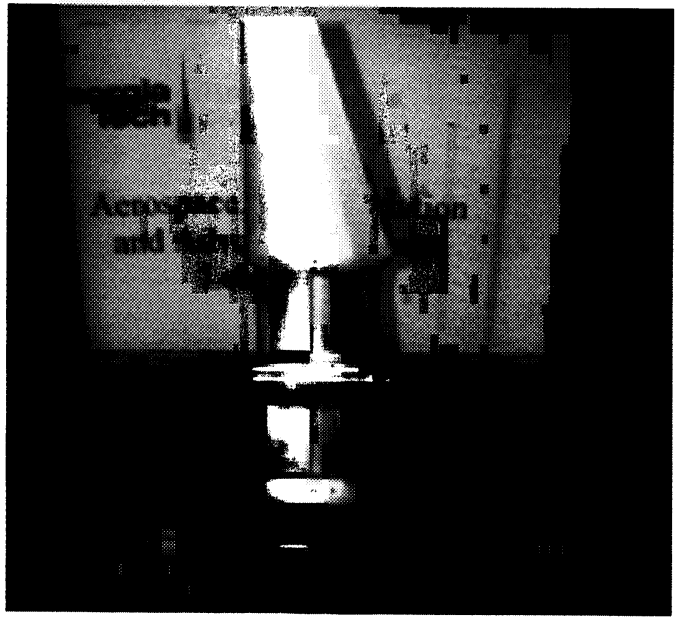

Prop $x / c=0.95 c$

Fig. 9 - Installed Semi-span Pneumatic Channel Wing Model with Variable Prop/Nacelle Locations

A series of evaluations was run to investigate variation in PCW configuration geometry. Figure 9 shows the range of movement available for the prop and nacelle assembly, with the prop plane located between $\mathrm{x} / \mathrm{c}=60 \%$ to 95\% of the channel chord. The Custer Channel Wing configurations had the propeller located at $\mathrm{x} / \mathrm{c}=100 \%$, the trailing edge, to take advantage of the prop inflow velocity over the longest channel surface. For the Pneumatic Channel Wing, a forward prop location was seen to be more effective during increases in both blowing and incidence, Figure 10. The apparent explanation is that the longer regime of higherspeed flow between prop and blowing slot provides greater suction on the upper surface. Note in Fig 10 that in order to compare the upper and lower plots, one must compare along lines of constant geometric angle of attack, $\alpha_{\text {geo }}$. Tunnel interference and wall corrections (Ref. 10) have been applied to geometric (set) incidence to yield the corrected $\alpha$ shown. The effect of reducing the gap clearance between the prop tip and channel is shown in Figure 11, where the smaller gap simply applies more prop slipstream near the channel walls. Conversely, it applies a better seal to the propeller tip.
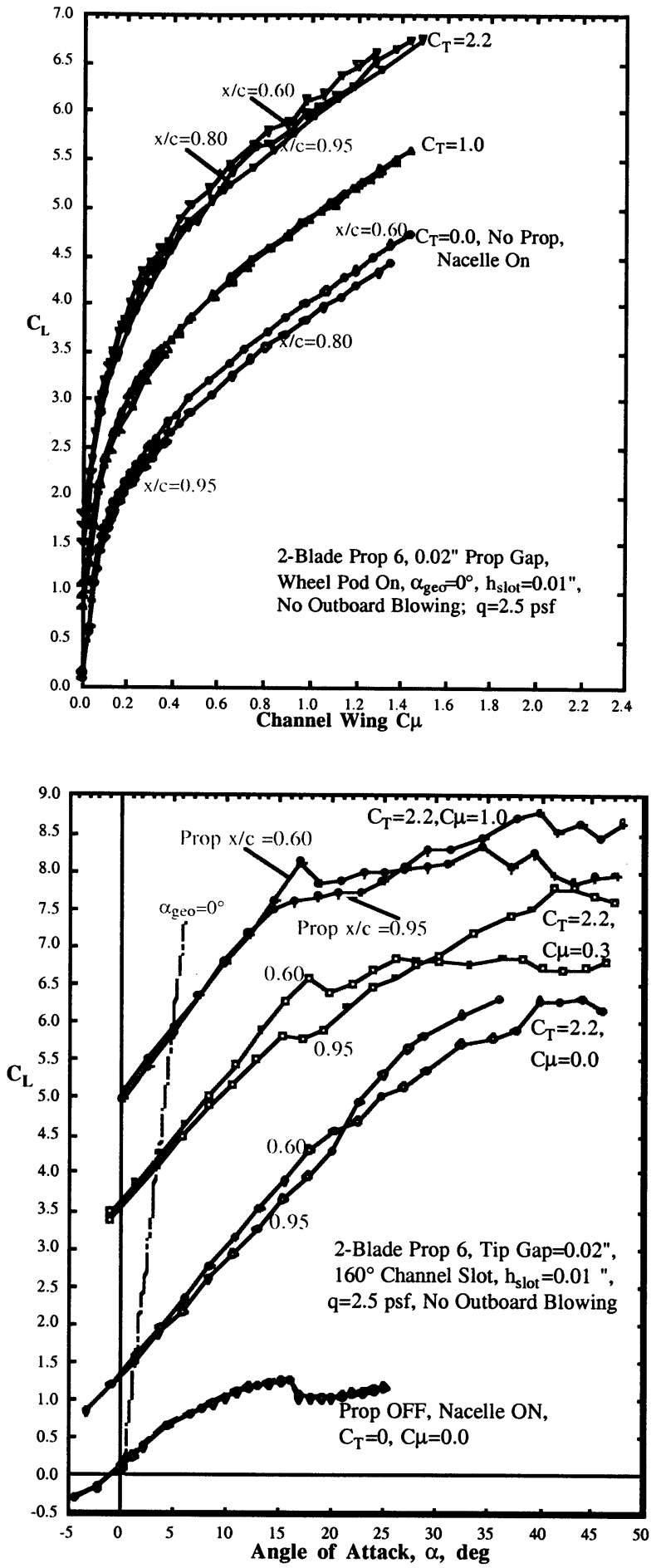

Fig. 10 - Effects of Prop/Nacelle Location on Lift and Stall Angle

Figure 12 shows the effect of increasing the circular arc length of the blown slot around the channel at a given $\mathrm{x} / \mathrm{c}$ value $(0.95 \mathrm{c})$, where the maximum slot arc of $160^{\circ}$ was most effective. Blowing of more than $160^{\circ}$ of channel arc was not appropriate on this model because the last $20^{\circ}$ of inboard arc was along the channel right next to the fuselage, and blowing 
there would do little more than bounce off the fuselage. Figure 13 also shows similar trends favoring a larger slot arc for the propeller-off blown channel configuration.

The effect on increased tail-off pitching moment caused by suction loading on the aft of the channel (either by blowing, prop slipstream, or both) is shown in Figure 14 as a function of $\mathrm{C}_{\mathrm{T}}$ and $\mathrm{C} \mu$, all at $\alpha=0^{\circ}$. These moments are referred to the channel's quarter-chord location (c/4), and confirm the typical trend of this type of blown configuration: large nose-down $\mathrm{C}_{\mathrm{M}}$ which, while it does make the aircraft much more stable longitudinally, causes concern with pitch trim. It is for this reason that additional experimental evaluations will soon be done tail-on (and possibly with the tail blown) to investigate increased longitudinal trim capabilities. All data presented herein have been tail-off. Also a second investigation will be conducted with leading-edge blowing installed on the outboard wing $\mathrm{CCW}$ portion to provide counteracting nose-up pitch for trim, as well as for leading-edge separation prevention. Furthermore, blowing on the forward-swept trailing edge of the blown $\mathrm{CCW}$ section outboard will also aid here by moving the blowing suction peaks forward, creating less nose-down pitch.

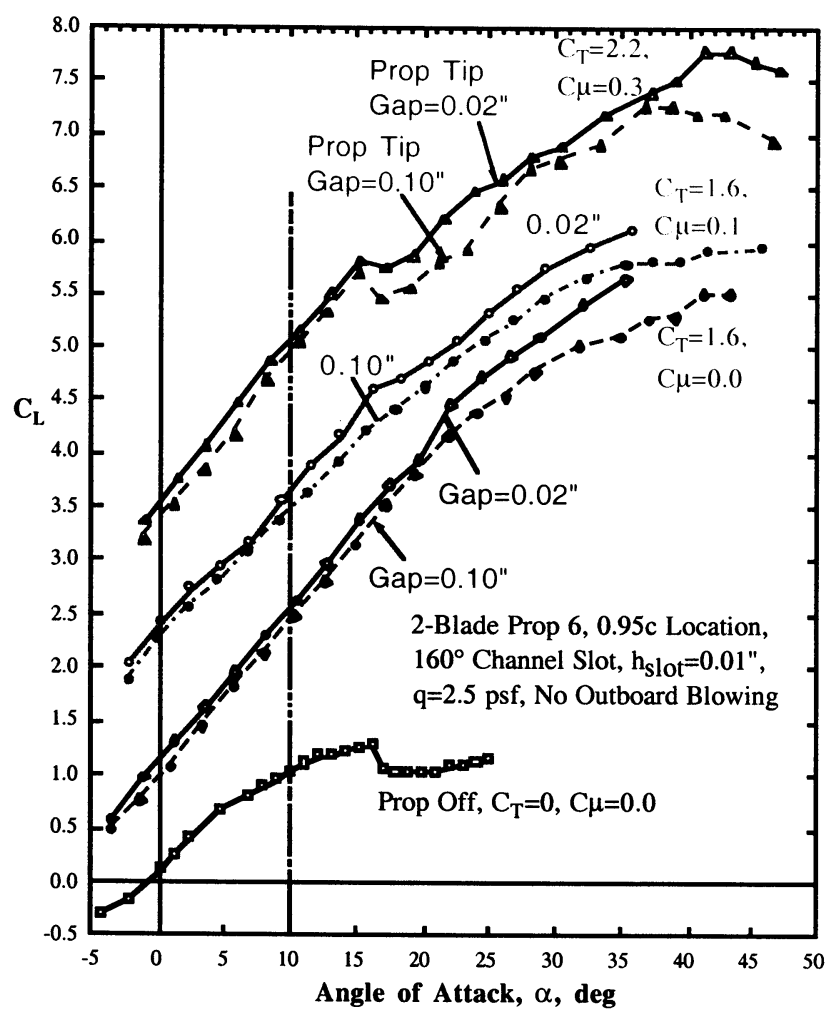

Fig. 11 - Effects of Propeller Tip Clearance on Lift Coefficient and Stall Angle

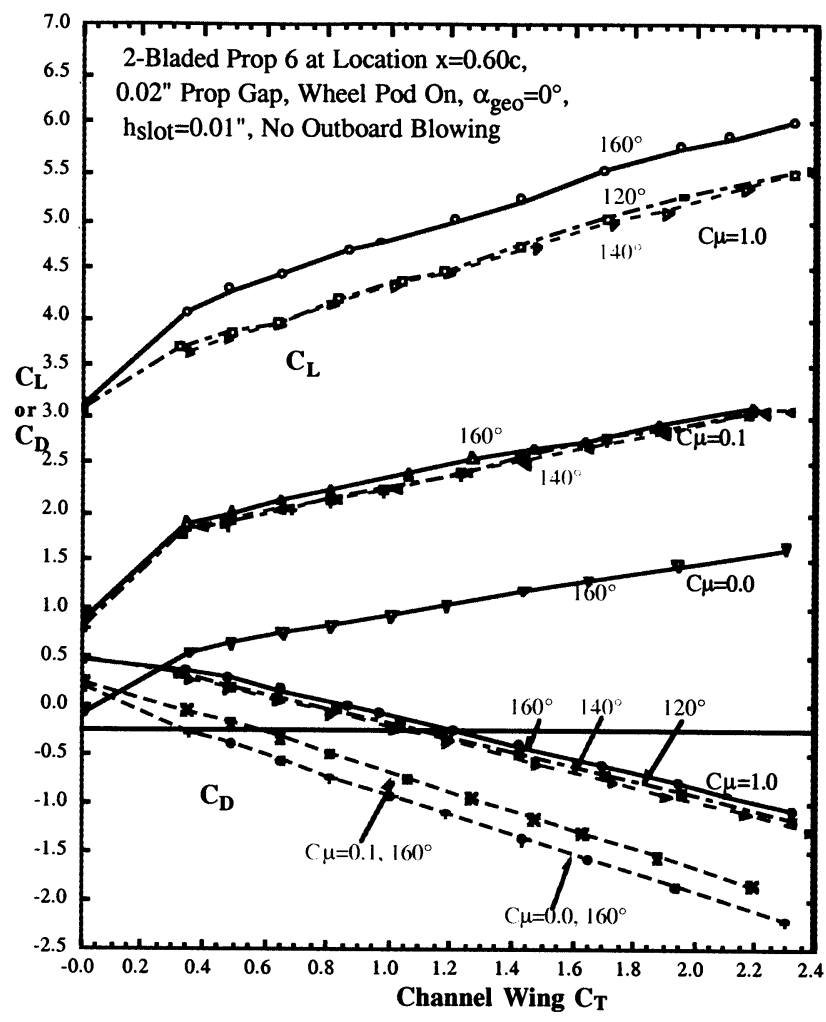

Fig. 12 - Effects on Lift and Drag of Varying Blown Channel Slot Arc Length at Constant $\mathrm{C} \mu$ and at $\alpha=0^{\circ}$, with Propeller and Nacelle Installed

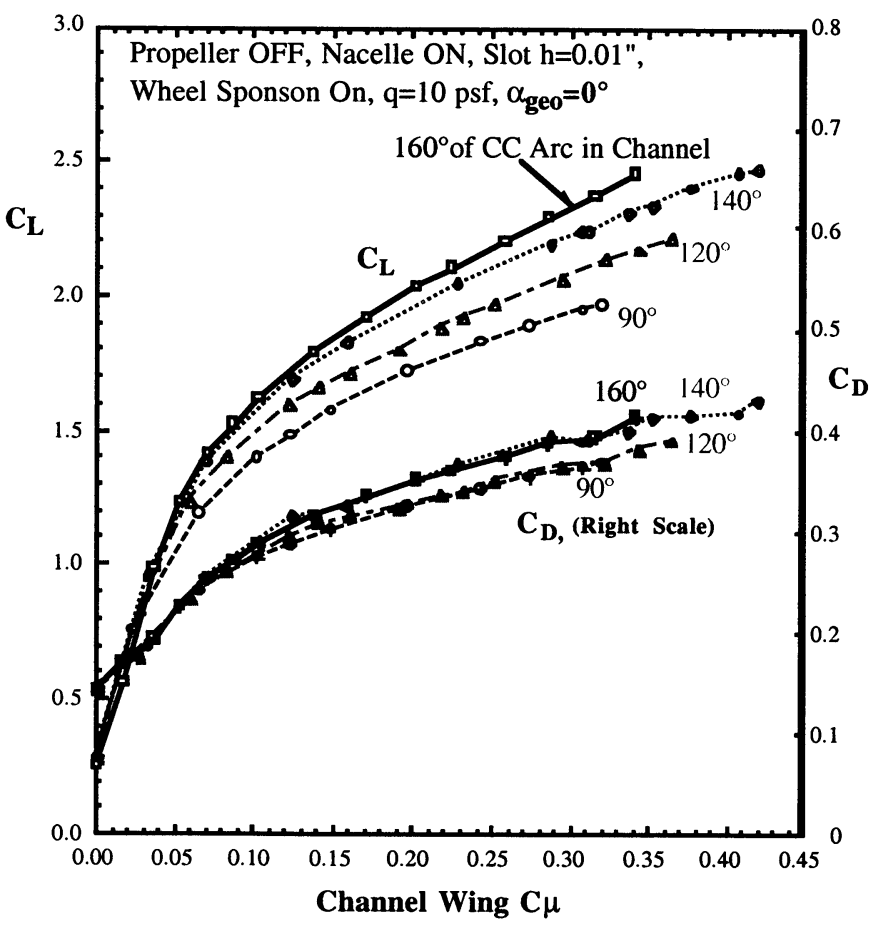

Fig. 13 - Effects on Lift and Drag of Varying Blown Channel Slot Arc Length at Constant $\mathrm{C} \mu$ at $\alpha=0^{\circ}$, with Propeller Removed but Nacelle Installed 


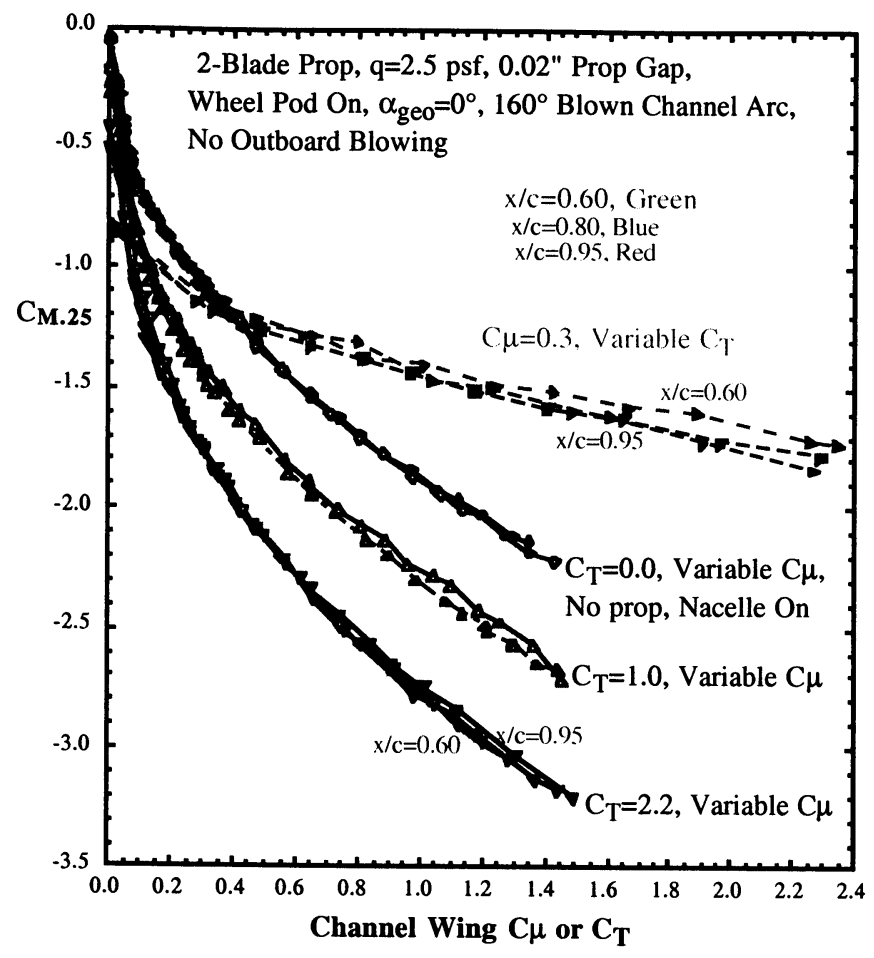

Fig. 14 - Effects of Prop/Nacelle Location, Blowing and Thrust on Quarter-Chord Pitching Moment, $\alpha=0^{\circ}$

\section{COMPARISQN of MEASUREMENTS and . PREDICTIONS}

In Figure 15 are compared the results of these investigations with previously-predicted lift and drag data which were estimated from existing CCW/USB wind-tunnel data and from A-6/CCW flight-test data. Whereas the prop/electric motor currently available did not allow higher $\mathrm{C}_{\mathrm{T}}$ values than about 2.4 , this lower-thrust wind-tunnel data considerably surpasses the predicted lift data (Fig. 15a). The experimental drag data (Fig. 15b) is similar to the predicted values at lower $\mathrm{C} \mu$ but shows less drag than predicted at higher blowing. These estimated data had been used to predict SuperSTOL takeoff distances on a hot day at $3000 \mathrm{ft}$ altitude to be less than 100 feet and in some instances, zero feet (see Reference 9). The measured versus predicted results in Figure 15 seem to suggest than even better takeoff performance might be obtained. However, the lower measured drag values indicate that additional attention will need to be paid to obtaining greater drag values for steeper glide slopes and shorter approaches. The upcoming tests at GTRI of a blown CCW wing section outboard are expected to yield very high induced drag (only when desired and chosen by the pilot), and should confirm the ability of the CCW outboard to vary drag from lower values (for takeoff or cruise) to much higher values for Super-STOL approaches.

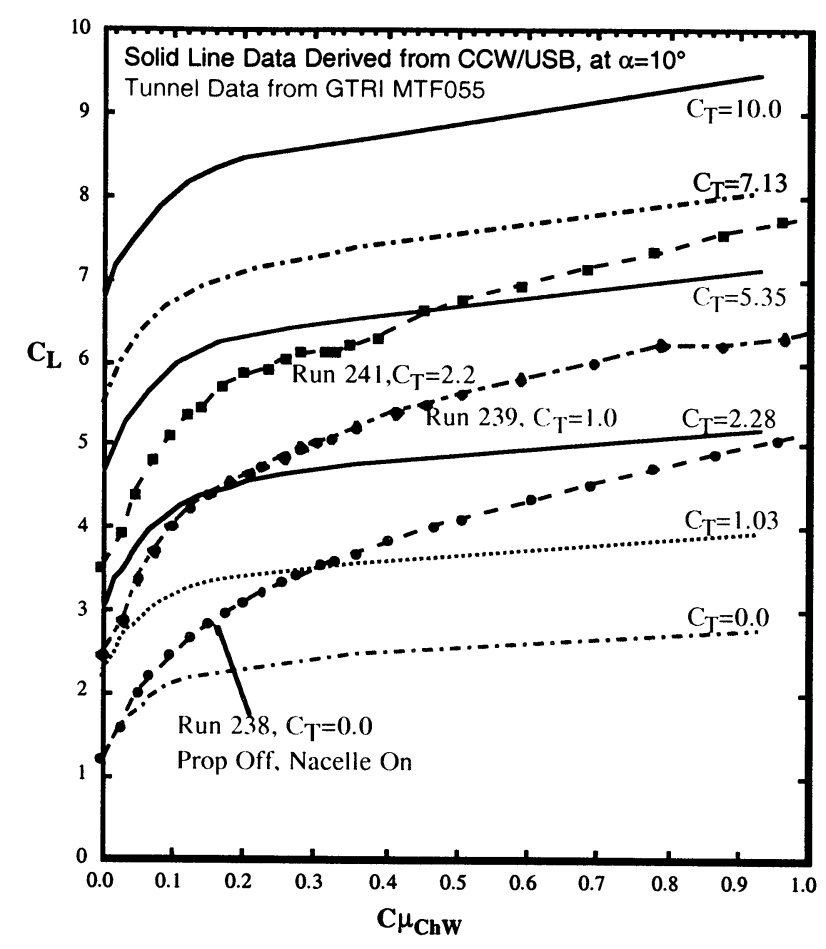

Fig. 15 - Comparisons of Predicted and Experimental PCW Lift \& Drag Data , $\alpha=10^{\circ}$

a. Measured vs Predicted Lift from Blowing at Constant $C_{T}$

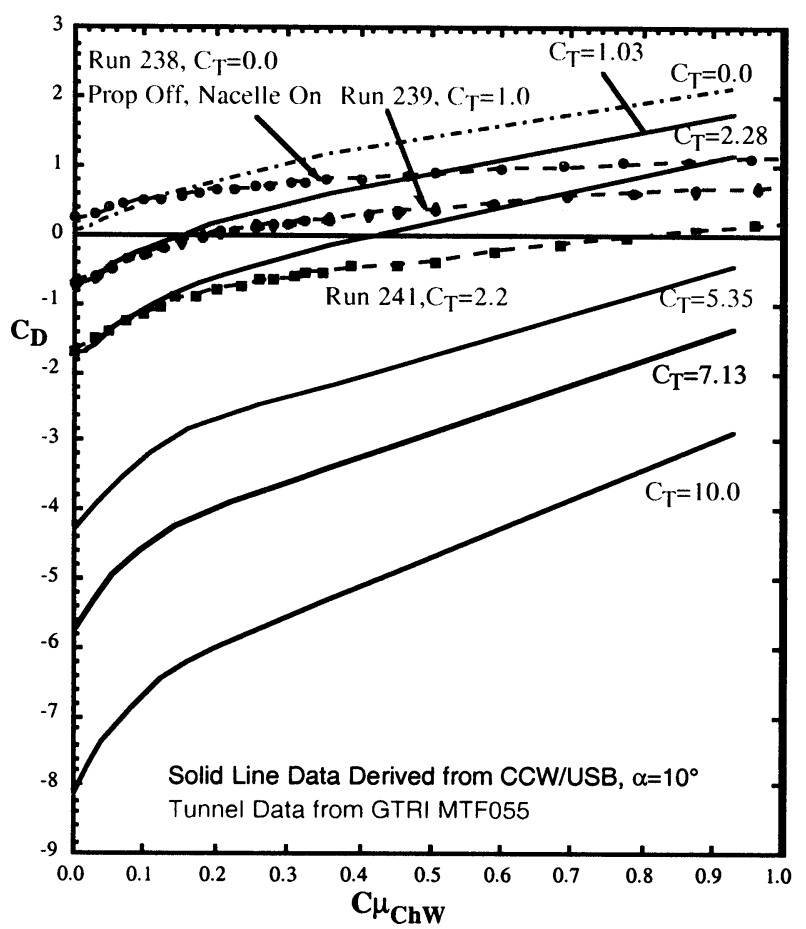

Fig. 15 - Comparisons of Predicted and Experimental PCW Lift \& Drag Data , $\alpha=10^{\circ}$

b. Measured vs Predicted Drag from Blowing at Constant $C_{T}$ 


\section{POTENTIAL APPLICATIONS}

Design and mission studies conducted at NASA LaRC based on the above tunnel data have lead to consideration of several new pneumatic powered-lift PCW-type configurations. The capability of the Pneumatic Channel Wing to significantly augment lift, drag, and stall angle to the levels reported herein demonstrates that this technology has the potential to enable simple/reliable/effective STOL and possibly VTOL operations of personal and business-sized aircraft operating from remote or small sites as well as increasingly dense urban environments. Such capability now opens the way for alternate visions regarding civilian travel scenarios, as well as both civilian and military aerial missions. One such vision is represented by the Personal Air Vehicle Exploration (PAVE) activity at NASA, Langley Research Center. Another vision, a military Super-STOL transport, is discussed in the mission study of Reference 9.

\section{SUMMARY and CONCLUSIONS}

Results from subsonic wind-tunnel investigations conducted at GTRI on a 0.075 -scale powered semi-span model of a conceptual Pneumatic Channel Wing transport have confirmed the potential aerodynamic payoffs of this possible Super-STOL configuration. These results include:

- Lift and drag augmentations and reductions as desired for Super-STOL operation have been confirmed, with $\mathrm{C}_{\mathrm{L}}=8.5$ measured at $\alpha=10^{\circ}$ and $C_{T}=2.2$, and drag coefficient (including thrust) varying between -2 and +2 , depending on blowing and thrust levels.

- Both blowing $(\mathrm{C} \mu)$ and thrust $\left(\mathrm{C}_{\mathrm{T}}\right)$ variations were found to significantly enhance circulation, thrust deflection and lift; but, evaluated as incremental lift per unit of input thrust or momentum $\left(\mathrm{C}_{\mathrm{T}}\right.$ or $\left.\mathrm{C} \mu\right)$, blowing was far more efficient than thrust.

- The blown channel wing itself, without thrust applied, was able to double the $\mathrm{C}_{\mathrm{L} \max }$ capability of the baseline aircraft configuration, and multiply its lift at $\alpha=0^{\circ}$ by a factor of 10. Addition of blowing on the outboard CCW section should increase this further, but could also add drag as needed for Super-STOL approaches.

- Even with the unblown outboard wing stalling at $\alpha=15^{\circ}-17^{\circ}$, the blown and thrusting channel increased lift up to a stall angle of $40^{\circ}-45^{\circ}$. While this may not prove practical as a takeoff/landing operational incidence, it does show significant improvement over the asymmetric LE separation of the conventional channel wing's stalled channel and the resulting low-speed control problems.

- Significant changes in lift and drag performance can also be made with geometric variations in propeller location, prop tip gap, and blowing slot arc length.
- By varying only $\mathrm{C} \mu$ and/or $\mathrm{C}_{\mathrm{T}}$, all the aircraft's aerodynamic characteristics can be augmented or reduced as desired by the Super-STOL aircraft's pilot or it's control system without mechanical moving parts (such as tilting rotors or wings) and without resorting to high $\alpha$ to acquire larger vertical thrust components to lift.

- Conversion of thrust into either drag decrease or drag increase without moving parts is also quite promising.

- Large nose-down pitching moments are produced by these blown configurations, and thus longitudinal trim needs to be addressed in future evaluations.

- In addition to the military Super-STOL transports discussed above, NASA LaRC has included these experimental data and pneumatic technology results in preliminary design studies of other possible pneumatic powered-lift configurations, including smaller personal and business-type aircraft.

Thus far, the projected operational benefits based on these early data suggest Super-STOL and possible VSTOL capability with significantly increased payload, reduced noise signatures, and increased engine-out control, all without variable geometry or mechanical engine/prop tilting. A Pneumatic Channel Wing aircraft thus equipped could provide a simpler, less costly way of achieving the Super STOL/VSTOL capability without the complexity, weight or reliability issues of rotating the propulsion system, carrying large engines and rotors on the wing tips, or thrusting downwards on fixed wings during hover. Additionally, the integration of pulsed-blowing technology with Circulation Control (currently being investigated by GTRI and NASA, Refs. 11 and 12) may further increase lift efficiency and reduce already low blowing requirements by up to $50 \%$ more, while further enhancing stability and control. Successful application of these results can lead to positive technology transfer to personal, business, and military sized aircraft.

\section{RECOMMENDATIONS}

Future testing, evaluation and development still need to be accomplished to address possible pitch-trim problems, performance at higher $\mathrm{C}_{\mathrm{T}}$ and lower $\mathrm{C} \mu$, and associated stability and control. In the future, the existing model should be modified to include horizontal tail surfaces and additional improvements to the pneumatic thrust deflection system. The following should be experimentally investigated:

- Use of pulsed blowing to reduce required blowing mass flows (both inboard and outboard).

- Higher propulsor solidity for greater thrust and powered lift, or improved propeller characteristics for greater thrust availability.

- Further evaluation of low-speed controllability and trim, including evaluation of the appropriate tail surfaces, which might even be blown to reduce tail area and drag. 
- Further evaluation of low-speed controllability and trim by novel aerodynamic/ pneumatic trim devices

The earlier mission analyses should be revised to incorporate the experimentally developed aeropropulsive and stability \& control characteristics of the Pneumatic Channel Wing concept. If the projected benefits are confirmed, and further benefits come to light, then larger-scale, higherReynolds-number testing on a full-3-D Pneumatic Channel Wing model with variable yaw capability should be conducted to facilitate greater strides toward technology maturation.

\section{REFERENCES}

1. Pasamanick, Jerome, "Langley Full-Scale-Tunnel Tests of the Custer Channel Wing Airplane," NACA RM L53A09, National Advisory Committee for Aeronautics, April 1953.

2. Mitchell, Kent A., "Mr. Custer and His Channel Wing Airplanes," Journal of American Aviation Historical Society, Spring 1998.

3. Blick, Edward. F, and Vincent Homer, "Power-on Channel Wing Aerodynamics," AIAA Journal of Aircraft, Vol. 8, No. 4, pp. 234-238, April 1971.

4. Englar, Robert J., "Circulation Control Pneumatic Aerodynamics: Blown Force and Moment Augmentation and Modification; Past, Present and Future," AIAA Paper 2000-2541, AIAA Fluids 2000 Meeting, Denver, CO, June 19-22, 2000.

5. Englar, R. J. and C. A. Applegate, "Circulation Control A Bibliography of DTNSRDC Research and Selected Outside References (Jan. 1969 through Dec. 1983)," DTNSRDC-84/052, September 1984.

6. Englar, R. J., "Development of Circulation Control Technology for Powered-Lift STOL Aircraft," NASA CP2432, "Proceedings of the 1986 Circulation Control Workshop".

7. Englar, R. J., J. H. Nichols, Jr., M. J. Harris, J. C. Eppel, and M. D. Shovlin, "Development of Pneumatic Thrust-Deflecting Powered-Lift Systems," AIAA Paper No. 86-0476, AIAA 24th Aerospace Sciences Meeting, Reno, Nevada, January 6-9, 1986.

8. Pugliese, A. J. (Grumman Aerospace Corporation) and R. J. Englar (DTNSRDC), "Flight Testing the Circulation Control Wing," AIAA Paper No. 79-1791, AIAA Aircraft Systems and Technology Meeting, August 1979.

9. Hines, N., A. Baker, M. Cartagena, M. Largent, J. Tai, S. Qiu, N. Yiakas, J. Zentner and R. J. Englar, "Pneumatic Channel Wing Comparative Mission Analysis and Design Study, Phase I," GTRI Technical Report, Project A-5942, March 22, 2000.
10. Englar, R. J. and R.M. Williams, "Test Techniques for High Lift Airfoils with Boundary Layer and Circulation Control for Application to Rotary Wing Aircraft," Canadian Aeronautics and Space Journal, Vol. 19, No. 3, pp. 93-108, March, 1973.

11. Englar, R. J., Niebur, C. S., and Gregory, S. D., "Pneumatic Lift and Control Surface Technology for High Speed Civil Transport Configurations," AIAA Journal of Aircraft, Vol. 36, No.2, pp. 332-339, March-April, 1999.

12. Jones, G. S., "An Active Flow Circulation Controlled Flap Concept for General Aviation Aircraft Applications," AIAA Paper No. 2002-3157, AIAA Flow Control Conference, June 24-26, 2002 